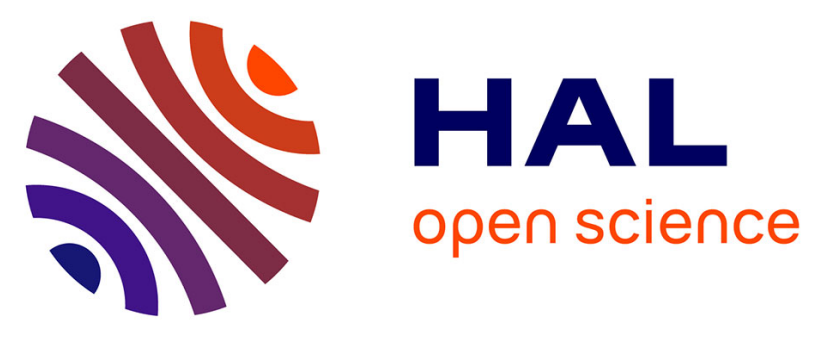

\title{
Referral pathway of patients aged 75 years and older after a telephone triage by the French emergency medical communication center (SAMU)
}

Adélaïde Vincent, Nathalie Jomard, Julie Haesebaert, Brigitte Comte, Thomas Gilbert, Anne-Marie Schott

\section{To cite this version:}

Adélaïde Vincent, Nathalie Jomard, Julie Haesebaert, Brigitte Comte, Thomas Gilbert, et al.. Referral pathway of patients aged 75 years and older after a telephone triage by the French emergency medical communication center (SAMU). Archives of Gerontology and Geriatrics, 2019, 84, pp.103893 -. 10.1016/j.archger.2019.05.018. hal-03484966

\section{HAL Id: hal-03484966 https://hal.science/hal-03484966}

Submitted on 20 Dec 2021

HAL is a multi-disciplinary open access archive for the deposit and dissemination of scientific research documents, whether they are published or not. The documents may come from teaching and research institutions in France or abroad, or from public or private research centers.
L'archive ouverte pluridisciplinaire HAL, est destinée au dépôt et à la diffusion de documents scientifiques de niveau recherche, publiés ou non, émanant des établissements d'enseignement et de recherche français ou étrangers, des laboratoires publics ou privés.

\section{(ㄷ)(1) $\$$}

Distributed under a Creative Commons Attribution - NonCommercial| 4.0 International 
Referral pathway of patients aged 75 years and older after a telephone triage by the French Emergency Medical Communication Center (SAMU).

Adélaïde VINCENT, MD ${ }^{1}$, Nathalie JOMARD, MD², Julie HAESEBAERT, MD ${ }^{3,6}$, Brigitte COMTE, $\mathrm{MD}^{4}$, Thomas GILBERT, MD ${ }^{5}$, Anne-Marie SCHOTT, MD, $\mathrm{PhD}^{3,6}$

Hospices Civils de Lyon, Edouard Herriot Hospital, Acute Medical Geriatric Unit; Lyon, France, ${ }^{2}$ Hospices Civils de Lyon, Lyon Sud Hospital, Geriatric Medical Team, Lyon, France,

${ }^{3}$ Hospices Civils de Lyon, Pôle "Information Médicale Evaluation Recherche” (IMER), Public Health, Lyon, France

4 Edouard Herriot University Hospital, Short Stay Geriatric Unit, Lyon, France,

5 Lyon Sud University Hospital, Short Stay Geriatric Unit, Lyon, France, 6HeSPeR unit, EA 7425, University Claude Bernard Lyon1P

Corresponding Author:

VINCENT, Adélaïde; Edouard Herriot university hospital, Place d'Arsonval 69437 Lyon cedex 03, France adelaide.vincent@chu-lyon.fr

Phone: 0033472119788, fax:0033472119567

Alternate Corresponding Author:

JOMARD, Nathalie; Lyon-Sud University Hospital, 165 chemin du grand Revoyet 69495 PierreBenite Cedex nathalie.jomard@chu-lyon.fr

Phone: 0033478861860, fax: 003347885682

\section{Running head: Referral pathway for elderly people after a triage by the ECC}




\section{ABSTRACT}

OBJECTIVES: To map the referral pathways of elderly people after telephone calls to Emergency Medical Communication Centers (ECC) in France.

DESIGN: Retrospective observational study.

SETTING: ECC and Emergency Departments (ED) of the Rhone region in France in 2013.

PARTICIPANTS: Patients aged 75 years and older who called or had calls made to the ECC on 7 non-consecutive days $(\mathrm{n}=712)$.

MEASUREMENTS: All calls made by/for patients aged 75 and over were analyzed. Data were collected regarding geriatric assessment and patient discharge destination after admission to an ED. RESULTS: All 4168 calls received over the 7 days were analyzed. Of these, 692 involved the care of elderly people and were included. The median call duration was $2 \min 59$ [1 $\min 57 ; 4 \min 13]$. Following the call, $35 \%$ of the patients remained at home, $62 \%$ were referred to ED and $3 \%$ were directly hospitalized in intensive care units. Of the patients admitted to ED, $73 \%$ had a stable clinical condition and the main reason for admission was a fall (28\%). Following ED care, $56 \%$ of patients were hospitalized and $44 \%$ returned directly home.

CONCLUSION: Over half the elderly patients included in this study were referred to an ED after a call to ECC. For half of them, their clinical condition was considered stable and they were discharged after the ED visit. A more appropriate assessment of clinical conditions among geriatric patients could help to improve patient triage during ECC calls, and therefore reduce ED referrals.

Keywords: Emergency Medical Service Communication Systems - elderly - Triage - Emergency Service, Hospital-care pathway 


\section{INTRODUCTION}

The number of elderly people is constantly growing, accompanied by a considerable increase in multiple chronic disease conditions and risks of decompensation (1). Consequently, they account for an ever-increasing proportion of patients in the emergency care system (2). According to a national study carried out in 2013 in the United States, more than one third of EMS (Emergency Medical Services) patients were over 65 years old (3). Furthermore, Emergency Departments (ED) continue to see increased admission of elderly patients. In 2010, an international review reported that people aged 75 years and over accounted for $12-24 \%$ of ED visits (4). This situation impacts the health system, increases congestion in ED, and prolongs waiting periods in ED. This leads to the risk of medical and functional complications for elderly patients due to prolonged consultation waiting times in ED (5-8).

While ED should be exclusively focused on urgent care, they are increasingly being used as a means of access to the health care system for elderly patients with stable health conditions (9-11). Alternatives could be the development of specific geriatric pathways and improved home-care $(12,13)$. Currently, $80 \%$ of hospitalizations of elderly patients in France are not scheduled, and occur after a visit in an ED (14). In various studies, the rate of inappropriate ED visits (i.e. for non-urgent situations), for elderly patients varied between $11.4 \%$ in Italy (15), $23.4 \%$ in Turkey (16) and $32 \%$ in France (17). Paradoxically, in France, $67-75 \%$ of patients were referred by general practitioners (GP) or by Emergency Medical Communication Centers (ECC) $(17,18)$ ECC are free public call centers, which operate 7 days a week 24 hours a day and respond to all health emergency calls for a defined area. They are the French equivalent of 911 in the USA. A trained ECC communication officer answers all calls and provides first-line assessment (19). He/she then prioritizes the call and connects the caller either to a general practitioner or to a physician with emergency care skills, according to standardized guidelines and the severity of the situation. The doctor then consults the caller over the phone and may send an appropriate care service to the patient (home medical visit, firefighters, 
private ambulance or ECC medicalized vehicles) (20-22). The ECC may improve the outcomes of elderly patients in the emergency chain. Optimizing geriatric assessment during calls to ECC could improve the relevance of ECC patient referrals to ED, and may offer more suitable alternatives.

To our knowledge, no study to date has focused on the outcomes of elderly patients after calling ECC in France. In the present study, we analyzed the ECC medical telephone triage of patients aged 75 years. The main objective was to follow the referral pathway of these patients, from the ECC call right up to their discharge destination following their visit in an ED. We also aimed to determine the profile of elderly patients most likely to be referred to an ED after ECC triage, and to compare it with that of patients who remained at home. 


\section{METHODS}

\section{Setting and study design}

A retrospective descriptive study was conducted in the ECC of the Rhône area of France (ECC69). Because no digital information exchange system currently exists between the ECC and the different ED in the area, our analysis had to be performed retrospectively. Individuals aged 75 years and over managed by ECC69 were selected on 7 non-consecutive days between the 1st of April 2012 and the 31th of March 2013. Days were randomly selected throughout the 12-month period to take into account weekly and seasonal variations in the number of calls.

\section{Population}

All calls made by/for patients aged 75 years and older during the 24 hours of each of the seven randomly selected days were extensively analyzed. Calls were excluded if they did not lead to a medical assessment, i.e. declarations of death, inter-hospital transfers, case already being handled by a different ECC, and callers hanging up before the medical decision on referral was made.

ECC procedure stipulates that all users be initially put in contact with an On-Call Medical Communication Officer who then connects the caller either to a physician with emergency care skills or a general practitioner, depending on the nature of the situation (emergency or primary care).

\section{Data collection}

All the data were collected by AV and NJ, resident general practitioners specialized in geriatric medicine. They retrospectively listened exhaustively to all audio-recordings of calls by/for elderly patients to ECC 69, and collected associated data in pre-drafted case report forms with coded fields. In order to create a comprehensive geriatric profile, the items chosen in the case report forms were selected following a study of the literature and from expert advice provided by physicians with emergency care skills and geriatric physicians. More specifically, the following data were collected 
for each of the ECC calls: demographic data (age, sex), hour and day of the call, duration of symptoms (more or less than 24 hours), and reason for the call -i.e. trauma (falls and wounds) or medical reasons (other than falls or wounds). Geriatric-based data included: the caller (patient/relative/health-professional), the patient's place of residence (home or nursing home), the presence or absence of next-of-kin living at home (yes/no), level of dependence (need for human aid), ability to walk alone or with help, history of hospitalization within the previous 3 months, presence of multiple pathologies (more than 3 concomitant chronic conditions), and polymedication (more than 3 medications for chronic conditions). The case report form was inspired by items in the Identification of Seniors at Risk (ISAR) tool (23).

In order to determine the patients' referral pathway, all telephone calls regarding each individual case were considered (including the initial ECC call, emergency transport request, and first responders' (e.g., firefighter, Emergency Medical Technician) reports. Additional data on the patient's acute condition and management were collected from the ED medical files for those referred to an ED, and from the Clinical Classification of Patients in Emergency (CCPE) tool, which is used in French ED's after medical examination to assess clinical severity at discharge (24). Furthermore, the duration of the stay in ED (time between the administrative admission of the patient and the validation of their discharge by the doctor), and the discharge destination of the patient, were recorded.

\section{Data analysis}

All data were analyzed anonymously. Data fields for which no data were available were categorized under 'not available' (N/A). Qualitative data were described as numbers and frequencies and compared using the $\mathrm{Chi}^{2}$ test or the Fisher's exact according to their application conditions. Quantitative data were expressed as mean \pm standard deviation, and analyzed using the Student t-test or presented with median [Inter-quartile range (IQR)] and compared using the Wilcoxon test, as 
appropriate, for non-normal distributions. We used univariate and multivariate analyses to analyze the association between patient geriatric profile variables and the risk of being referred to an ED. Odds ratios (OR) and their $95 \%$ confidence intervals were calculated by univariate and multivariate logistic regression models. Variables presenting an association with a p-value $<0.20$ in the univariate analysis were included in the multivariate model, which modelled the risk of being referred to an ED. All tests were two-tailed and a p-value $<0.05$ was considered significant. All analyses were performed using the SAS 9.2 software (SAS Institute Inc., Cary, NC, USA).

\section{RESULTS}

Of the 4,168 calls made to ECC 69 during the 7 days of the study, 712 (17\%) involved patients aged 75 years and over, of whom 20 were excluded for the following reasons: death $(n=9)$, secondary referral $(n=4)$, telephone assessment by another ECC $(n=3)$, patient already hospitalized $(n=1)$, mistaken age $(n=2)$, patient hanging up before the medical decision on referral was taken $(n=1)$. Overall, 692 calls were included.

The median call duration was $2 \min 59$ [1min57; 4min13]. Following the 692 calls, 229 fire fighters, 223 private ambulances, and 41 ECC medicalized vehicles were dispatched.

\section{Patients' pathway}

From the 692 calls to the ECC, 426 patients (61.6\%) were sent to $22 \mathrm{ED}, 24$ (3.4\%) were referred to intensive care units and $242(35.0 \%)$ stayed at home (72 of these received medical advice, 109 had home medical visits and 62 were assessed by private ambulances). After the ED visit, 188 patients were sent back home directly, while 250 patients were hospitalized. The complete patient pathway is described in Figure 1.

\section{Patient profiles}


Table 1 shows patient and call characteristics. Medical and traumatic problems accounted for $74.7 \%$ and $25.3 \%$ of ECC calls, respectively. The main symptoms reported were shortness of breath, unconsciousness, fever, chest pain, and behavior disorder. Falls represented $23.8 \%$ of all calls. Of all those included, $40.9 \%$ were dependent in some way, $34.2 \%$ had multiple pathologies and $84.1 \%$ lived at home. Missing data on geriatric information collected by ECC dispatcher reached $19.5 \%$ for physical dependence and $39.8 \%$ for multiple pathologies because these data were not collected during the call.

\section{Factors associated with ED referrals}

Table 1 describes the demographic and geriatric criteria between two groups defined according to referral patterns after the ECC call: patients sent to an ED $(n=426)$ and patients who remained at home $(\mathrm{n}=242)$. Multivariate analysis indicated that the 8 a.m. -6 p.m. time period $(\mathrm{p}=0.039)$, a context of trauma $(\mathrm{p}=0.029)$, being managed on call by an emergency physician $(\mathrm{p}<0.001)$ and residing in a nursing home $(\mathrm{p}=0.039)$, were parameters that significantly and independently increased the risk of patients being sent to an ED (Table 2).

\section{ED stays}

The duration of an ED stay ranged from 13 minutes to 23 hours 10 minutes, with a median of $4 \mathrm{hr} 34$ $\min$ [IQR $2 \mathrm{hr} 37 \mathrm{~min} ; 6 \mathrm{hr} 58 \mathrm{~min}$ ]. The time spent in an ED was shorter when the reasons for calling were trauma-based: 3 hr 15 min [2 hr 05 min; 5 hr $01 \mathrm{~min}$ ] (versus 5 hr 03 min [2 hr 37 min; $6 \mathrm{hr} 58 \mathrm{~min}$ ] for medical-based reasons $(\mathrm{p}=0.005)$, while it was significantly longer when the patient was subsequently hospitalized: the median was $5 \mathrm{hr} 00 \mathrm{~min}$ [3 $\mathrm{hr} 08 \mathrm{~min} ; 7 \mathrm{hr} 45 \mathrm{~min}$ ] (versus $3 \mathrm{hr} 24 \mathrm{~min}$ [1 hr $51 \mathrm{~min} ; 5 \mathrm{hr} 58 \mathrm{~min}]$ when the patient returned home (p < 0.001)). According to the ED records, $10.1 \%$ of the patients were categorized as CCPE1 (stable clinical condition or not requiring further examination), 63.0\% as CCPE2 (stable clinical condition requiring further 
investigation), $22.4 \%$ as CCPE 3 (clinical condition which may be aggravated but not life threatening) and $4.5 \%$ as CCPE 4 or 5 (life threatening). 


\section{DISCUSSION}

We studied 692 ECC calls by/for elderly patients received over 7 non-consecutive days. Nearly 2 out of 3 patients were referred to an ED. More than $50 \%$ of the latter were subsequently considered clinically stable during their ED stay. Furthermore more than 50\% were discharged home. It is important to note that not all those considered stable were discharged home. Of all 692 patients, $36 \%$ were hospitalized, directly from the ECC call or after an ECC-referred ED visit.

\section{Number of calls and response by ECC}

Elderly patients represented $17 \%$ of all ECC calls studied however the estimated rate of people over 75 years was $9.1 \%$ in France. The aging demographic in France implies that the number of older patients triaged in ECC or attending hospitals - especially ED - will increase in the near future $(1,25)$. How the healthcare system is going to adapt to this evolution is a matter of great concern $(1,3,26)$. The large proportion of patients being discharged home after an ECC-referred visit to an ED, underlines the need to implement robust strategies that ensure that patients referred to ED really require urgent hospital care. For other patients, i.e. not requiring urgent hospital care, there needs to be an alternate choice.

At the ECC level, the distinction between real and perceived medical emergencies can sometimes be challenging. It is possible that the telephone-based exchanges are harder for elderly patients due to communication problems, poorer overall health conditions, and complex psycho-social situations (27). Moreover, training and experience of the communication officer also impact the decision to refer the patient to ED or not, GPs less likely referring patients to ED than emergency physicians. However, because of the very short call duration allowed (set by the total daily number of calls the ECC is required to answer) only limited information can be collected. A study on another French ECC found that median duration of calls was 96 seconds (28), while yet another study highlighted a mean call duration with the ECC communication officer of $107+/$ - 45 seconds (19), when studying all incoming ECC calls. The longer call duration in our ECC study (median call duration of 179 
seconds for elderly patients) would suggest that a more detailed assessment was performed, but our results suggest that this was not the case, as important geriatric information, such as dependency or multiple pathologies, were often not recorded.

\section{Patients' referral pathway after ECC call}

Sixty-one percent of patients from all calls were referred to an ED. Thirty percent of the latter were sent for a trauma-based problem. This high proportion could be related to the fact that the vast majority of calls were for falls $(29,30)$, which are a recognized geriatric syndrome and a common reason for admission to ED. Trauma-based problems represented $15 \%$ of older patients' ED visits $(4,31,32)$. The percentage of fall-related ED visits increased with age (33).

Based on collected data, we were able to determine three main circumstances under which the patients were sent to ED. \#1: Real emergency needing urgent hospital care, \#2: Need for technical support (e.g. stitches following a cut, complementary tests or imaging), \#3: Medico-psycho-social evaluation: situation for which it is impossible to collect reliable data by telephone, unavailability or saturation of existing primary care alternatives. While the appropriateness of ED stays was not considered in our study, because it was not part of the study objective, the profiles of older patients attending ED and the relevance of being referred to an ED have both been the subject of numerous studies $(6,14,31,34-37)$. It has been suggested for example, that some visits by elderly patients to ED could be avoidable and that inappropriate ED stays can cause a lengthening of the average transit time in $\operatorname{ED}(5,38)$, which in turn can have negative consequences for all patients $(5,38,39)$. Ambulatory alternatives to ED are available in several countries (13) during opening hours to offer paramedical assessment or rapid geriatric evaluation, and ECC could refer patients to such structures. Some of our findings suggest that ECC in France do not effectively filter ED visits. First, $43 \%$ of patients sent to an ED were discharged home. The same rate was found in another study regarding all ED visits by elderly patients (40). As we only studied patients referred to an ED after an ECC call where a physician made a telephone-based assessment, one might have expected a lower discharge 
rate. Second, we found that $10 \%$ of patients referred to ED after ECC calls were classified as CCPE1 (did not have a para-clinical evaluation), which is substantially higher than the $3.5 \%$ found in the French National Study of Users of the Emergency Department, which included referred and spontaneous ED visits of elderly patients (41). These findings suggest that although patients were assessed on the phone by an experienced physician, this did not lead to ED referral being avoided for patients who did not really need emergency care. This result underlines the need to improve geriatric evaluation and physicians' decision-making referral processes during ECC calls, by developing specific care strategies and training. Such strategies would include the setting-up of alternative care pathways, be they home-based or ambulatory, while training would include improvements to the ECC management process itself - e.g., fine-tuning the selection of geriatric patients to be sent to ED, all the while keeping the call length short in order to cope with the numerous calls received.

Other gerontology-related elements could also be incorporated into the management process, to help improve the telephonic assessment of patients, provide better knowledge of existing care structures and improve coordination for ambulatory patients. In France, geriatric hotlines have already been developed specifically for health professionals (GP or nurses) regarding the management of elderly patients $(42,43)$. International initiatives in this field could inform future strategies to help improve French ECC efficiency. In Australia, for example, a network of specialized geriatric nurse practitioners is available for both institutionalized and community-dwelling elderly patients $(44,45)$. Other non-emergency phone numbers that have been developed to respond to specific demands, such as \#111 proposed by the U.S NIH (National Institutes of Health) (46), could also represent an interesting alternative, providing a more thorough evaluation and better tailored referral of patients to alternative services to ED. In France, a specific platform has been developed connecting ECC physicians to a dedicated pediatric nurses in the same office who can provide information to callers in order to avoid unnecessary pediatric ED visits (47). This platform provides parents with standardized information and advice concerning fever, diarrhea, crying, head trauma, and respiratory 
obstruction in young infants. All these strategies and interventions could be adapted and developed to create a new system, which meets the needs of elderly patients more comprehensively.

\section{Hospitalization}

In this study, a third of patients calling the ECC were hospitalized, and 3\% of all ECC calls led to direct admission to an ICU (Intensive Care Units) or resuscitation unit. This confirms that ECC does indeed adequately manage life-threatening emergencies for older patients. Results from international literature have helped identify the situations which necessitate maximum intensive medical care for elderly people $(46,47)$. Secondary transfer to an ICU after an ED stay (8\% of the elderly patients in our study) could either reflect a worsening of the patient's condition during his/her stay in an ED, or illustrate the difficulties reported by ECC officers in referring patients directly to an ICU (48).

Half of the patients sent to an ED in our study were eventually hospitalized. This figure is higher than that found in international data studying the admission rate of patients aged 65 years and over in the 1990 s $(6,36,40,48,49)$. Twenty percent of the patients sent to the ED via the ECC were managed in an Acute Medical Unit (AMU) before being transferred to another unit. This confirms the buffer role of these structures $(50,51)$. This must raise awareness on the risk of a vicious circle exists, whereby delayed care for the elderly increases hospitalization time, raises the risks of physical dependency and thereby increases the costs of healthcare $(5,8)$.

Although the high admission rate may reflect a need for hospital care for many patients calling ECC, many visits to ED could be avoided by alternatives to hospitalization or a direct system connection between the ECC and the geriatricians, which could directly set up admissions to geriatric wards (beneficial for both the patients and the flow in ED (7)). Recently, dedicated geriatric call center hotlines for professionals, manned by geriatric physicians, have been implemented to help organize direct short-stays in geriatric units, ambulatory care, and home visits, in collaboration with general practitioners. $(42,43)$. One study reported that patients sent to short-stay geriatric units are identical 
to those sent to ED with regards to the CCPE classification and geriatric characteristics (52). In some cases, when the ECC physician answering a call feels that the patient's condition does not warrant an emergency requiring urgent ambulance transfer, alternative care pathways may be more relevant that ED referral. In our setting ECC physicians were able to avail of the geriatric hotlines mentioned above to schedule the prompt hospitalization of the patient. This may represent a better alternative and prevent unnecessary ED visits.

\section{Limitation}

To our knowledge, no study to date has specifically analyzed the medical telephone triage and referral of elderly patients by French ECC. Some limitations need to be addressed. Firstly, our study was conducted in only one ECC in France. However, due to the centralized organization of the ECC in the country, the territory covered is large. The fact that patients were sent to the ED of 22 different hospitals within this territory extends the generalizability of the study. Second, we only studied the flow of patients referred to ED directly by ECC officer, while patients left at home could also report to ED on their own following the call. However, patients left at home were not followed up after the ECC call and it was not feasible to determine whether they had visited an ED after the decision to leave them at home.

\section{CONCLUSION}

In our observational study, two out of three patients aged 75 and over, requesting assistance through the ECC, were sent to an ED in the absence of an alternate choice. Most of these patients were in a stable condition and many of them were discharged home. This illustrates the complexity and difficulty of the current geriatric ECC call management system in France. Our findings highlight the need to develop specific alternative pathways to reduce ECC-based referrals to ED for older patients. ECC could become an additional element of the geriatric care management sector, by integrating evaluation tools to help the decision process, training ECC physicians in geriatric profiles, and 
creating partnerships with geriatric sectors (e.g., hotlines, mobile geriatric services). These possibilities open the way for further research to assess the impact of such integration strategies on the healthcare management system. 


\section{ACKNOWLEDGMENT}

We thank Jude Sweeney for the English revision and editing of the manuscript. 


\section{REFERENCES}

1. Forouzanfar MH, Afshin A, Alexander LT, Anderson HR, Bhutta ZA, Biryukov S, et al. Global, regional, and national comparative risk assessment of 79 behavioural, environmental and occupational, and metabolic risks or clusters of risks, 1990-2015: a systematic analysis for the Global Burden of Disease Study 2015. The Lancet. oct 2016;388(10053):1659-724.

2. Laplanche D, Nolevaux G, Villenet N, Monneret T, Devillard A, Hugerot A. Evolution of visiting emergency departments by elderly, immediate referral postconsultation. J Eur Urgences. 2007;20(1):21.

3. Wang HE, Mann NC, Jacobson KE, Ms MD, Mears G, Smyrski K, et al. National characteristics of emergency medical services responses in the United States. Prehospital Emerg Care Off J Natl Assoc EMS Physicians Natl Assoc State EMS Dir. mars 2013;17(1):8-14.

4. Samaras N, Chevalley T, Samaras D, Gold G. Older Patients in the Emergency Department: A Review. Ann Emerg Med. sept 2010;56(3):261-9.

5. Ackroyd-Stolarz S, Guernsey JR, Mackinnon NJ, Kovacs G. The association between a prolonged stay in the emergency department and adverse events in older patients admitted to hospital: a retrospective cohort study. BMJ Qual Saf. 2011;20(7):564-569.

6. Latham LP, Ackroyd-Stolarz S. Emergency department utilization by older adults: a descriptive study. Can Geriatr J. 2014;17(4):118.

7. Bailleux S, Oualid H, Bouaziz D, Tardieux P-M, Levraut J. Influence of attendance at an emergency department (ED) by people aged over 75 years on the lenght of stay in ED. J Eur Urgences. 2007;20(1):38.

8. Lang P-O, Drame M, Mahmoudi R, Jolly D, Laniece I, Saint-Jean O, et al. Frailty: learnings from the SAFEs cohort study and future perspectives for the research. Geriatr Psychol Neuropsychiatr Vieil. 2011;9(2):135-149.

9. Lowthian JA, Smith C, Stoelwinder JU, Smit DV, McNeil JJ, Cameron PA. Why older patients of lower clinical urgency choose to attend the emergency department: Older lower urgency patients in the ED. Intern Med J. janv 2013;43(1):59-65.

10. Afilalo J, Marinovich A, Afilalo M, Colacone A, Léger R, Unger B, et al. Nonurgent emergency department patient characteristics and barriers to primary care. Acad Emerg Med Off $\mathbf{J}$ Soc Acad Emerg Med. déc 2004;11(12):1302-10.

11. Carret MLV, Fassa AG, Kawachi I. Demand for emergency health service: factors associated with inappropriate use. BMC Health Serv Res. 18 août 2007;7:131. 
12. Coleman EA, Eilertsen TB, Kramer AM, Magid DJ, Beck A, Conner D. Reducing emergency visits in older adults with chronic illness. A randomized, controlled trial of group visits. Eff Clin Pract ECP. avr 2001;4(2):49-57.

13. Pines JM, Hilton JA, Weber EJ, Alkemade AJ, Al Shabanah H, Anderson PD, et al. International perspectives on emergency department crowding. Acad Emerg Med Off J Soc Acad Emerg Med. déc 2011;18(12):1358-70.

14. Sough B, Gauthier T, Clair D, Le Gall A, Menecier P, Mangola B. People aged 75 and over in the emergency department. Gériatrie Psychol Neuropsychiatr Vieil. 2012;10(2):151-158.

15. Bianco A, Pileggi C, Angelillo IF. Non-urgent visits to a hospital emergency department in Italy. Public Health. juill 2003;117(4):250-5.

16. Gulacti U, Lok U, Celik M, Aktas N, Polat H. The ED use and non-urgent visits of elderly patients. Turk J Emerg Med. déc 2016;16(4):141-5.

17. Petitot C, Chapuis F, Touzet S, Fournier G, Bonnefoy M. Inappropriate consultation of elderly subjects attending an emergency ward of a university hospital: a prospective study. Rev Gériatrie. 2008;33(9):761-769.

18. Société Française de Médecine d'Urgence. Support for the elderly over 75 years in the emergency department. J Eur Urgences. 2004;17(3):183-201.

19. Montassier E, Labady J, Andre A, Potel G, Berthier F, Jenvrin J, et al. The Effect of Work Shift Configurations on Emergency Medical Dispatch Center Response. Prehosp Emerg Care. 3 avr 2015;19(2):254-9.

20. Adnet F, Lapostolle F. International EMS systems: France. Resuscitation. oct 2004;63(1):7-9.

21. Giroud M, Pateron D. Medical regulation: the French National Authority for Health (HAS) lays down recommendations on the management of calls. Ann Fr Médecine Urgence. janv 2012;2(1):4-6.

22. Bagou G, Berthier F, Bertrand C, Comte G. Classification des degrés d'urgence en régulation. Guide d'aide à la régulation au SAMU Centre 15 (2). In: 2nde éd. SFEM Editions; 2009.

23. McCusker J, Bellavance F, Cardin S, Trepanier S, Verdon J, Ardman O. Detection of Older People at Increased Risk of Adverse Health Outcomes After an Emergency Visit: The ISAR Screening Tool. J Am Geriatr Soc. oct 1999;47(10):1229-37.

24. Fourestié V, Roussignol E, Elkharrat D, Rauss A, Simon N. Clinical classification of emergency patients: definition and reproducibility. Réanimation Urgences. janv 1994;3(5):573-8. 
25. INSEE. Demographic balance sheet 2016 [Internet]. France; Disponible sur: https://www.insee.fr/fr/statistiques/1892086?sommaire=1912926

26. Goldstein J, Jensen JL, Carter AJE, Travers AH, Rockwood K. The Epidemiology of Prehospital Emergency Responses for Older Adults in a Provincial EMS System. CJEM. sept 2015;17(5):491-6.

27. Vergne M. Medical telephone triage for elderly. Congrès Urgences Paris. 2011;19:1-17.

28. Penverne Y, Leclere B, Labady J, Berthier F, Jenvrin J, Javaudin F, et al. Key performance indicators' assessment to develop best practices in an Emergency Medical Communication Centre: Eur J Emerg Med. mai 2017;1.

29. Salvi F, Mattioli A, Giannini E, Vita D, Morichi V, Fallani M, et al. Pattern of use and presenting complaints of older patients visiting an Emergency Department in Italy. Aging Clin Exp Res. oct 2013;25(5):583-90.

30. Keskinoglu P, Sofuoglu T, Ozmen O, Gündüz M, Ozkan M. Older people's use of prehospital emergency medical services in Izmir, Turkey. Arch Gerontol Geriatr. juin 2010;50(3):35660.

31. Lazarovici C, Somme D, Chatellier G, Saint-Jean O, Espinoza P. Initial pattern of elderly patients and effect on their orientation after their visit in the emergency departments. Results from a national study. Rev Med Interne. 2008;29(8):618-625.

32. Roussel-Laudrin S, Paillaud E, Alonso E, Caillet P, Herbaud S, Merlier I, et al. The establishment of geriatric intervention group and geriatric assessment at emergency of Henri-Mondor hospital. Rev Med Interne. 2005;26(6):458-466.

33. Albert M, McCaig LF, Ashman JJ. Emergency Department Visits by Persons Aged 65 and Over: United States, 2009-2010. NCHS Data Brief. oct 2013;(130).

34. Derame G, El Kouri D, Hamidou M, Carré E, Potel G. Non-justified visits to emergency units. Proposal of differentiated care. Presse Médicale. 2004;33(12):780-783.

35. Pines JM, Mullins PM, Cooper JK, Feng LB, Roth KE. National Trends in Emergency Department Use, Care Patterns, and Quality of Care of Older Adults in the United States. J Am Geriatr Soc. janv 2013;61(1):12-7.

36. Gruneir A, Silver MJ, Rochon PA. Emergency Department Use by Older Adults: A Literature Review on Trends, Appropriateness, and Consequences of Unmet Health Care Needs. Med Care Res Rev. 9 sept 2010; 
37. Lowthian JA, Curtis AJ, Jolley DJ, Stoelwinder JU, McNeil JJ, Cameron PA. Demand at the emergency department front door: 10-year trends in presentations. Med J Aust. 6 févr 2012;196:12832.

38. Freund Y, Yordanov Y, Vincent-Cassy C, Riou B, Ray P. Old patients wait longer in the emergency department. J Am Geriatr Soc. août 2012;60(8):1592-3.

39. Émond M, Grenier D, Morin J, Eagles D, Boucher V, Le Sage N, et al. Emergency Department Stay Associated Delirium in Older Patients. Can Geriatr J CGJ. mars 2017;20(1):10-4.

40. Aminzadeh F, Dalziel WB. Older adults in the emergency department: A systematic review of patterns of use, adverse outcomes, and effectiveness of interventions. Ann Emerg Med. mars 2002;39(3):238-47.

41. Lanièce I, Couturier P, Dramé M, Gavazzi G, Lehman S, Jolly D, et al. Incidence and main factors associated with early unplanned hospital readmission among French medical inpatients aged 75 and over admitted through emergency units. Age Ageing. juill 2008;37(4):416-22.

42. Salles N, Floccia M, Videau M-N, Diallo L, Guérin D, Valentin V, et al. Avoiding Emergency Department Admissions Using Telephonic Consultations Between General Practitioners and Hospital Geriatricians. J Am Geriatr Soc. 1 avr 2014;62(4):782-4.

43. Legrain S, Tubach F, Bonnet-Zamponi D, Lemaire A, Aquino J-P, Paillaud E, et al. A new multimodal geriatric discharge-planning intervention to prevent emergency visits and rehospitalizations of older adults: the optimization of medication in AGEd multicenter randomized controlled trial. J Am Geriatr Soc. nov 2011;59(11):2017-28.

44. Hullick C, Conway J, Higgins I, Hewitt J, Dilworth S, Holliday E, et al. Emergency department transfers and hospital admissions from residential aged care facilities: a controlled prepost design study. BMC Geriatr [Internet]. déc 2016 [cité 17 août 2017];16(1). Disponible sur: http://bmcgeriatr.biomedcentral.com/articles/10.1186/s12877-016-0279-1

45. Arendts G, Sim M, Johnston S, Brightwell R. ParaMED Home: a protocol for a randomised controlled trial of paramedic assessment and referral to access medical care at home. BMC Emerg Med. 8 juin 2011;11:7.

46. NHS - Urgent and emergency care services in England [Internet]. Disponible sur: http://www.nhs.uk/NHSEngland/AboutNHSservices/Emergencyandurgentcareservices/Pages/NHS111.aspx

47. Stagnara J, Vermont J, Jacquel J, Bagou G, Masson S, Kassaï B, et al. Feasibility study of a call centre to reduce non-scheduled visits and unjustified consultations in pediatric emergencies units. Presse Médicale. nov 2010;39(11):e258-63. 
48. Roberts DC, McKay MP, Shaffer A. Increasing Rates of Emergency Department Visits for Elderly Patients in the United States, 1993 to 2003. Ann Emerg Med. juin 2008;51(6):769-74.

49. Richardson DB. Elderly patients in the emergency department: a prospective study of characteristics and outcome. Med J Aust. 17 août 1992;157(4):234-9.

50. Delmas G, Pierrard O, Weissenbach A, Zaioua S, Zemmouche P, Gillet P, et al. Short Stay Unit (SSU) and people aged 80 and over (80+). J Eur Urgences. 2008;21:A149-A150.

51. Scott I, Vaughan L, Bell D. Effectiveness of acute medical units in hospitals: a systematic review. Int J Qual Health Care J Int Soc Qual Health Care ISQua. déc 2009;21(6):397-407.

52. Neouze A, Dechartres A, Legrain S, Raynaud-Simon A, Gaubert-Dahan M-L, BonnetZamponi D. Hospitalization of elderly in an acute-care geriatric department. Gériatrie Psychol Neuropsychiatr Vieil. juin 2012;10(2):143-50. 


\section{Figures}

Figure 1: Referral pathway of patients aged 75 years and over from the French Emergency Medical Communication Centre after their stay in a hospital Emergency Department.

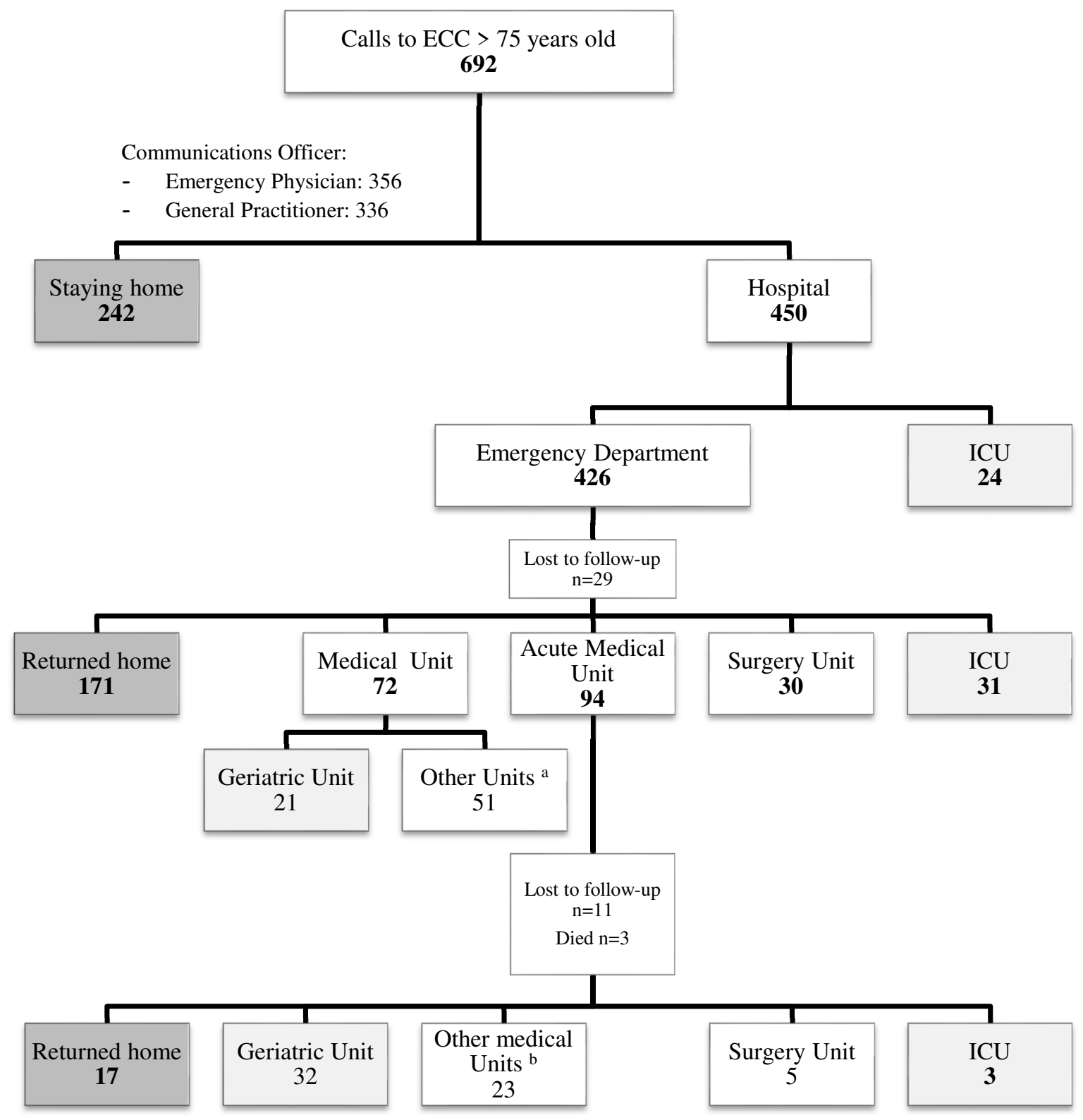

ICU: Intensive Care Unit

a: Cardiology ( $n=15)$, Multi-disciplinary Medicine ( $n=15)$, Internal Medicine $(n=7)$, Neurology ( $n=4)$, Rheumatology $(n=3)$, Pneumatology $(n=2)$, Hepato-Gastro-Enterology $(n=2)$, Nephrology $(n=1)$, Endocrinology $(n=1)$, Psychiatry $(n=1)$

b: Multi-disciplinary Medicine (n=13), Hepato-Gastro-Enterology ( $n=3)$, Pneumatology (n=2), Psychiatry ( $n=2)$, Cardiology $(n=1)$, Rheumatology $(n=1)$, Neurology $(n=1)$ 
Table 1: Description of patients'characteristics

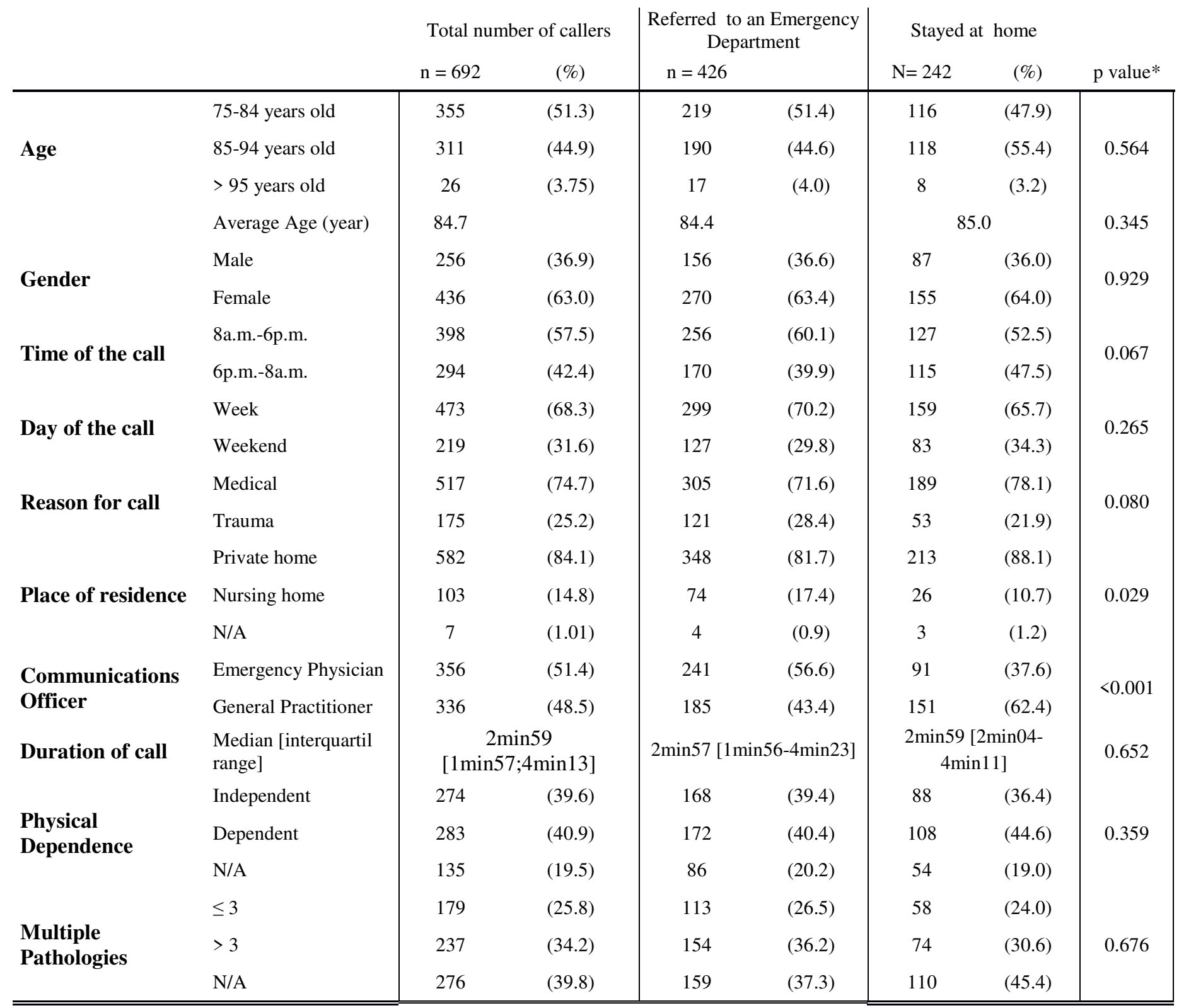

* p value for the comparison between patients sent to the ED and patients staying home

N/A: No answer 
Table 2: Univariate and multivariate analyses comparing the choice to refer a patient to an Emergency Department $(n=422)$ or to have the patient stay at home $(n=239)$.

\begin{tabular}{|c|c|c|c|c|c|c|c|}
\hline & & \multicolumn{3}{|c|}{ Univariate Analysis } & \multicolumn{3}{|c|}{ Multivariate Analysis $^{\mathrm{a}}$} \\
\hline & & $\begin{array}{c}\text { OR non } \\
\text { adjusted }\end{array}$ & IC $95 \%$ & $\mathbf{p}$ & $\begin{array}{c}\text { OR } \\
\text { adjusted }\end{array}$ & IC $95 \%$ & $\mathbf{p}$ \\
\hline \multirow{2}{*}{ Time of the call } & 6p.m.-8a.m. & 1 & & & & & \\
\hline & 8a.m.-6p.m. & 1.36 & {$[0.99 ; 1.87]$} & 0.056 & 1.4 & {$[1.01 ; 1.95]$} & 0.044 \\
\hline \multirow{2}{*}{ Reason for call } & Medical & 1 & & & & & \\
\hline & Trauma & 1.41 & {$[0.98 ; 2.05]$} & 0.066 & 1.25 & {$[0.85 ; 1.84]$} & 0.254 \\
\hline \multirow[b]{2}{*}{ Place of residence } & Home & 1 & & & 1 & & \\
\hline & $\begin{array}{l}\text { Nursing } \\
\text { home }\end{array}$ & 1.74 & {$[1.08 ; 2.81]$} & 0.023 & 1.76 & {$[1.08 ; 2.88]$} & 0.023 \\
\hline \multirow{2}{*}{$\begin{array}{l}\text { Communication } \\
\text { Officer* }\end{array}$} & $\begin{array}{l}\text { General } \\
\text { Practitioner }\end{array}$ & 1 & & & 1 & & \\
\hline & $\begin{array}{l}\text { Emergency } \\
\text { Physician }\end{array}$ & 2.63 & {$[1.77 ; 3.91]$} & $<0.001$ & 2.10 & {$[1.51 ; 2.93]$} & $<0.001$ \\
\hline
\end{tabular}

${ }^{a}$ the multivariate analysis included the following variables : time of the call, reason for call, place of residence, communication officer.

(7 patients were excluded because of missing data for place of residence). 